\title{
A Video Is Worth a Thousand Words
}

\author{
Kara Bischoff MD*, Wendy Anderson MD, Steve Z. Pantilat MD
}

Department of Medicine, University of California, San Francisco, San Francisco, California.

There is no doubt about the importance of assessing, documenting, and honoring patient wishes regarding care. For hospitalized patients, code status is a critical treatment preference to document given that the need for cardiopulmonary resuscitation (CPR) arises suddenly, outcomes are often poor, and the default is for patients to receive the treatment unless they actively decline it. Hospitalists are expected to document code status for every hospitalized patient, but admission code status conversations are often brief-and that might be all right. A code status discussion for a 70-year-old man with no chronic medical problems and excellent functional status who has been admitted for pain after a motor vehicle accident may require only an introduction to the concept of advance care planning, the importance of having a surrogate, and confirmation of full code status. On the other hand, a 45-year-old woman with metastatic pancreatic cancer would likely benefit from a family meeting in which the hospitalist could review her disease course and prognosis, assess her values and priorities in the context of her advanced illness, make treatment recommendations-including code status- that are consistent with her values, and elicit questions. ${ }^{1,2}$ We need to free up hospitalists from spending time discussing code status with every patient so that they can spend more time in quality goals of care discussions with seriously ill patients. The paradigm of the one doctor-one patient admission code status conversation for every patient is no longer realistic.

As reported by Merino and colleagues in this issue of JHM, video decision aids about CPR for hospitalized patients can offer an innovative solution to determining code status for hospitalized patients. ${ }^{3}$ The authors conducted a prospective, randomized controlled trial, which enrolled older adults admitted to the hospital medicine service at the Veteran's Administration (VA) Hospital in Minneapolis. Participants (N $=119$ ) were randomized to usual care or to watch a 6 -minute video that explained code status options, used a mannequin to illustrate a mock code, and provided information about potential complications and survival rates. Patients who watched the video were more likely to choose do not resuscitate/do not intubate status, with a large effect size (56\% in the intervention group vs. $17 \%$ in the control group, $P<0.00001$ ).

\footnotetext{
Address for correspondence and print requests: Kara Bischoff, MD, UCSF Department of Medicine, Box 0131, 533 Parnassus Ave, San Francisco, CA 94143; Telephone: 415-606-1041; Fax: 415-476-5020; E-mail: Kara.Bischoff@ ucsf.edu
}

Received: June 30, 2017; Accepted: June 30, 2017

2017 Society of Hospital Medicine DOI 10.12788/jhm.2792
This study adds to a growing body of literature about this powerful modality to assist with advanced care planning. Over the past 10 years, studies — conducted primarily by Volandes, El-Jawahri, and colleagues-have demonstrated how video decision aids impact the care that patients want in the setting of cancer, heart failure, serious illness with short prognosis, and future dementia. ${ }^{4-9}$ This literature has also shown that video decision aids can increase patients' knowledge about CPR and increase the stability of decisions over time. Further, video decision aids have been well accepted by patients, who report that they would recommended such videos to others. This body of evidence underscores the potential of video decision aids to improve concordance between patient preferences and care provided, which is key given the longstanding and widespread concern about patients receiving care that is inconsistent with their values at the end of life. ${ }^{10}$ In short, video decision aids work.

Merino and colleagues are the first to examine the use of a video decision aid about code status in a general population of older adults on a hospital medicine service and the second to integrate such a video into usual inpatient care, which are important advancements. ${ }^{2,3}$ There are several issues that warrant further consideration prior to widely disseminating such a video, however. As the authors note, the participants in this VA study were overwhelmingly white men and their average age was 75 . Further, the authors found a nonsignificant trend towards patients in the intervention group having less trust that "my doctors and healthcare team want what is best for me" (76\% in the intervention group vs. $93 \%$ in the control group; $P=0.083$ ). Decision making about life-sustaining therapies and reactions to communication about serious illness are heavily influenced by cultural and socioeconomic factors, including health literacy. ${ }^{11}$ It will be important to seek feedback from a diverse group of patients and families to ensure that the video decision aid is interpreted accurately, renders decisions that are consistent with patients' values, and does not negatively impact the clinician-patient relationship. ${ }^{12}$ Additionally, as the above cases illustrate, code status discussions should be tailored to patient factors, including illness severity and point in the disease course. Hospitalists will ultimately benefit from having access to multiple different videos about a range of advance care planning topics that can be used when appropriate.

In addition to selecting the right video for the right patient, the next challenge for hospitalists and health systems will be how to implement them within real-world clinical care and a broader approach to advance care planning. There are technical and logistical challenges to displaying 
videos in hospital rooms, and more significant challenges in ensuring timely follow-up discussions, communication of patients' dynamic care preferences to their surrogates, changes to inpatient orders, documentation in the electronic medical record where it can be easily found in the future, and completion of advance directives and Physician Orders for Life Sustaining Treatment forms to communicate patients' goals of care beyond the hospital and health system. Each of these steps is critical and is supported through videos and activities in the free, patient-facing, PREPARE web-based tool (https://www.prepareforyourcare.org/).2,13,14

\section{References}

1. Piscator E, Hedberg P, Göransson K, Djärv T. Survival after in-hospital cardiac arrest is highly associated with the Age-combined Charlson Co-morbidity Index in a cohort study from a two-site Swedish University hospital. Resuscitation. 2016;99:79-83.

2. Jain A, Corriveau S, Quinn K, Gardhouse A, Vegas DB, You JJ. Video decision aids to assist with advance care planning: a systematic review and meta-analysis. BMJ Open. 2015;5(6):e007491.

3. Merino AM, Greiner R, Hartwig K. A randomized controlled trial of a CPR decision support video for patients admitted to the general medicine service. J Hosp Med. 2017:12(9):699-703.

4. Volandes AE, Levin TT, Slovin S, Carvajal RD, O'Reilly EM, et al. Augmenting advance care planning in poor prognosis cancer with a video decision aid: a preintervention-postintervention study. Cancer. 2012;118(17):4331-4338.

5. El-Jawahri A, Paasche-Orlow MK, Matlock D, Stevenson LW, Lewis EF, Stewart G, et al. Randomized, ontrolled trial of an advance care planning video decision support tool for patients with advanced heart failure. Circulation. 2016;134(1):52-60.

6. El-Jawahri A, Mitchell SL, Paasche-Orlow MK, Temel JS, Jackson VA, Rutledge $\mathrm{RR}$, et al. A randomized controlled trial of a CPR and intubation video decision support tool for hospitalized patients. J Gen Intern Med. 2015;30(8):1071-1080.

7. Volandes AE, Ferguson LA, Davis AD, Hull NC, Green MJ, Chang Y, et al. Assessing end-of-life preferences for advanced dementia in rural patients using an educational video: a randomized controlled trial. J Palliat Med. 2011;14(2): 169-177.

8. Volandes AE, Paasche-Orlow MK, Barry MJ, Gillick MR, Minaker KL, Chang
The ubiquitous presence of videos in our lives speaks to their power to engage and affect us. Video decision aids provide detailed explanations and vivid images that convey more than words can alone. While there is more work to be done to ensure videos are appropriate for all hospitalized patients and support rather than detract from patient-doctor relationships, this study and others like it show that video decision aids are potent tools to promote better decision-making and higher value, more efficient care.

Disclosures: The authors have nothing to disclose.

Y, et al. Video decision support tool for advance care planning in dementia: randomised controlled trial. BMJ. 2009;338:b2159.

9. El-Jawahri A, Podgurski LM, Eichler AF, Plotkin SR, Temel JS, Mitchell SL, et al. Use of video to facilitate end-of-life discussions with patients with cancer: a randomized controlled trial. J Clin Oncol. 2010;28(2):305-310.

10. IOM (Institute of Medicine). Dying in America: Improving Quality and Honoring Individual Preferences Near the End of Life. Washington, DC: The National Academies Press; 2015.

11. Castillo LS, Williams BA, Hooper SM, Sabatino CP, Weithorn LA, Sudore RL. Lost in translation: the unintended consequences of advance directive law on clinical care. Ann Intern Med. 2011;154(2):121-128.

12. Anderson WG, Cimino JW, Lo B. Seriously ill hospitalized patients' perspectives on the benefits and harms of two models of hospital CPR discussions. Patient Educ Couns. 2013;93(3):633-640.

13. Sudore RL, Boscardin J, Feuz MA, McMahan RD, Katen MT, Barnes DE. Effect of the PREPARE website vs an easy-to-read advance directive on advance care planning documentation and engagement among veterans: a randomized clinical trial [published online ahead of print May 18, 2017]. JAMA Intern Med. 2017; May 18. doi: $10.1001 /$ jamainternmed.20171607.

14. Improving Communication about Serious Illness: Implementation Toolkit. SHM Center for Quality Improvement. Society of Hospital Medicine. 2017. http:// www.hospitalmedicine.org/Web/Quality___nnovation/Implementation_Toolkit/ EOL/Palliative_Care_Home_Society_of_Hospital_Medicine.aspx. Accessed June $13,2017$. 